J. Reprod. Fert. (1974) 38, 49-57

\title{
THE EFFECTS OF VARIOUS ANDROGENS ON PERIPHERAL STRUCTURES IN THE CASTRATED MALE RAT
}

\author{
R. F. PARROTT \\ Royal Veterinary College, Royal College Street, London $\mathcal{N W 1} 0 T U$
}

(Received 16th May 1973)

\begin{abstract}
Summary. A study was made of the relative abilities of propionates of eight naturally occurring androgens to maintain sexual accessory organ weights and numbers of penile spines in castrated adult male rats. Experiments involved daily treatment with either $150 \mu \mathrm{g} /$ day for 5 weeks starting on the day of castration or $300 \mu \mathrm{g} /$ day for 10 days starting 2 weeks after castration. The compounds tested were (a) testosterone, (b) dihydrotestosterone, (c) androstenedione, (d) androstanedione, (e) $3 \alpha$-androstanediol, (f) androsterone, (g) $3 \beta$-androstanediol, and (h) androstenediol and they fell into three activity groups: (1) highly effective $(a, b)$ as judged by all peripheral measures, (2) considerably less potent $(c, d, e, f)$ than Group 1, with a negligible effect on the seminal vesicles, and (3) no effect detected $(g, h)$. In general, the response of the penile spines followed that of the prostate and was equally sensitive.

The conclusions from these results were basically in agreement with studies using immature male rats.
\end{abstract}

\section{INTRODUCTION}

In the male rat, the accessory sexual organs are highly sensitive to levels of circulating androgens. For this reason, the castrated male rat has often been used for androgen assays (Dorfman, 1962). The penile spines of the male rat are androgen-dependent, castration causing a decrease in their size and number and treatment with exogenous androgens restoring normal morphology in both prepubertal (Lyons, Berlin \& Friedlander, 1942) and adult (Beach \& Levinson, 1950; Beach \& Nucci, 1970) castrates. The spines are small cornified structures projecting from the surface of the glans penis. Touch corpuscles are present near the bases of the spines and since the spines are likely to become more prominent with the stretching of the epithelium during erection, it has been suggested that they may function as tactile sense organs during copulation (Beach \& Levinson, 1950). If this is the case, castration would reduce penile sensitivity and this could affect sexual behaviour. Evidence for the rôle of sensory feedback from the penis during copulation is provided by the finding that, in the intact male rat, anaesthetization of the penis reduced intromission frequency without affecting the rate of mounting (Adler \& 
Bermant, 1966). This is similar to the effects of castration when intromissions decrease but rate of mounting may show a temporary increase (Davidson, 1966). It would appear, therefore, that peripheral androgenic stimulation may be a contributory factor in the maintenance of sexual behaviour, but it is not the only factor involved since treatment of castrated male rats with dihydrotestosterone-an androgen with a large peripheral effect-failed to restore sexual activity (McDonald and his co-authors, 1970; Feder, 1971).

In an investigation on the ability of androgens to maintain sexual behaviour in the castrated male rat, the peripheral effects of the androgens were also recorded as being of relevance to subsequent behavioural analysis, and allowing a determination of relative potencies. It was hoped also to draw some conclusions with regard to structure/activity relationships of the androgen molecule. This report describes the peripheral effects of eight naturally occurring androgens.

\section{MATERIALS AND METHODS}

\section{Experiments 1 to 4}

Fifty outbred male rats (275 to $300 \mathrm{~g}$ ) were used for each experiment. Animals were of Wistar derivation in Exps 1, 3 and 4 and SpragueDawley strain in Exp. 2. In each experiment, the rats were randomly divided into five equal groups. Treatments were as follows: castrated+oil vehicle; castrated + testosterone propionate, $75 \mu \mathrm{g} /$ day; castrated+androgen 1,150 $\mu \mathrm{g} /$ day; castrated + androgen $2,150 \mu \mathrm{g} / \mathrm{day}$; intact +oil. All treatments were given as five daily subcutaneous injections per week in $0.1 \mathrm{ml}$ corn oil, starting on the day of castration. Experiments lasted 5 weeks after which animals were killed and weighed. Seminal vesicles, prostates and penes were then removed. For each animal, wet weights were determined for paired seminal vesicles, empty of fluid and minus coagulating glands, and the ventral prostate gland. The penis was fixed in formol saline for $24 \mathrm{hr}$ after which it was dissected from the sheath and placed in Bouin's fluid for about 3 weeks. It was then decalcified in Pereny's fluid and sectioned at $10 \mu \mathrm{m}$, stained with haematoxylin and eosin and the number of penile spines was counted.

The androgens tested were: Exp. 1-dihydrotestosterone (5 $\alpha$-androstan-17 $\beta$ ol-3-one), androsterone ( $5 \alpha$-androstan-3 $\alpha$-ol-17-one); Exp. $2-3 \alpha$-androstanediol ( $5 \alpha$-androstan- $3 \alpha, 17 \beta$-diol), $3 \beta$-androstanediol ( $5 \alpha$-androstan-3,17 $\beta$-diol);

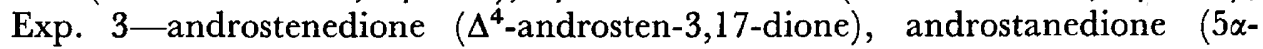
androstan-3,17-dione); Exp. 4-androstenediol ( $\Delta^{5}$-androsten-3,17 $\beta$-diol).

As it was anticipated that some of these compounds could be very weak in their action and to avoid using excessive amounts of steroid, all androgens were administered as their propionates. Those not commercially available in this form were propionated in the laboratory and checked for purity by thin-layer chromatography. The two diketones, androstenedione and androstanedione, were prepared as enol propionates.

\section{Experiment 5}

Thirty-five adult male Wistar rats were abdominally castrated and left for 14 days. They were then randomly allotted to seven equal groups and treated 


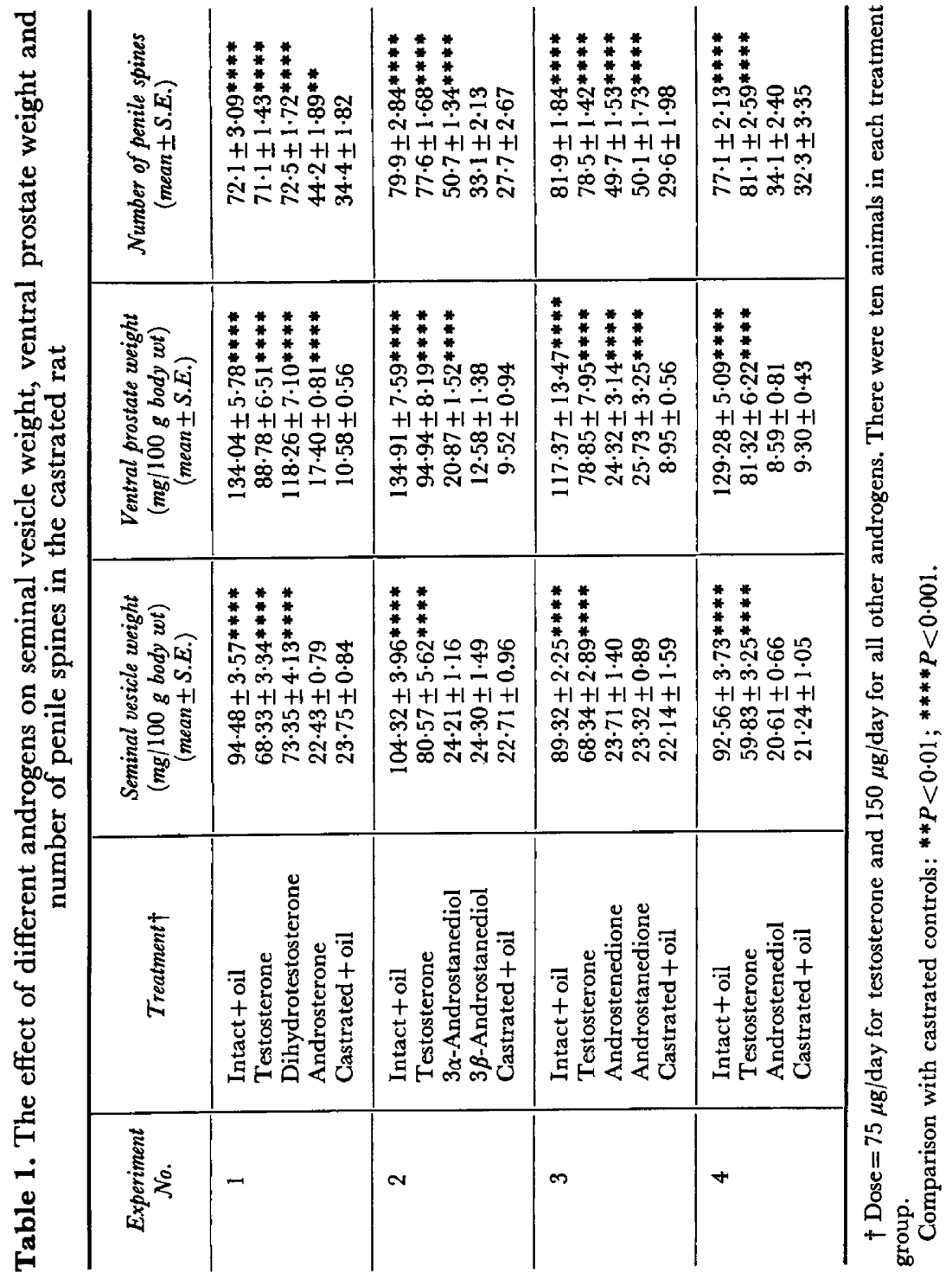


with the following androgens: Group 1 -testosterone, $\left(\Delta^{4}\right.$-androsten-17 $\beta$-ol3-one); Group 2-dihydrotestosterone; Group 3-androstenedione; Group 4 -androstanedione; Group 5-androsterone; Group 6-3 $\alpha$-androstanediol; Group 7-oil vehicle. All androgens were administered as their propionates for 10 days in doses of $300 \mu \mathrm{g} /$ day in $0.1 \mathrm{ml}$ corn oil. The animals were then killed and the accessory sex organ weights were determined as described above.

\section{RESULTS}

Some of the results have been presented in a preliminary communication (Parrott, 1972). The results of the present study were analysed with Student's $t$ test and those for Exps 1 to 4 are presented in Table 1. After 5 weeks, highly significant differences $(P<0.001)$ were detected between intact and castrated controls for all three measures in each experiment. In Exp. 1, dihydrotestosterone propionate, at a dose of $150 \mu \mathrm{g} /$ day, maintained a normal number of penile spines and nearly normal seminal vesicle and ventral prostate weights. Testosterone propionate ( $75 \mu \mathrm{g} /$ day) was less effective with regard to accessory sex organ weights. Androsterone propionate at the same dose as dihydrotestosterone had no effect on seminal vesicle weights and a small significant effect on the prostate and penile spines.

In Exp. 2, $3 \beta$-androstanediol propionate had no demonstrable effects while $3 \alpha$-androstanediol propionate caused significant increases in prostate weight and the number of penile spines. This effect was minimal compared to that of testosterone propionate administered in half the dose.

In Exp. 3, androstenedione and androstanedione propionates had similar effects. Neither affected the seminal vesicles but both caused significant increases in prostate weight and number of penile spines. Both compounds were less potent than testosterone.

In Exp. 4, androstenediol propionate was ineffective in maintaining any of the accessory structures above castrated control levels.

The effects of these different androgens are summarized in Text-fig. 1. Relative organ weights and numbers of penile spines are expressed as a percentage of intact controls for the experiment in which they were studied. Testosterone propionate is omitted as it was given at half the dose of the other androgens. Results show that penile spine numbers decreased less rapidly after castration than the weights of the accessory sex glands. The results also suggest that, under the experimental conditions used, the various androgens can be divided into three categories: (1) compounds with a large peripheral effect; (2) compounds with a small effect on only the prostate and penile spines; (3) compounds with no effect. To confirm this, it was decided to compare the active compounds (Groups 1 and 2) with oil controls in a further experiment (Exp. 5); the results are given in Table 2. Testosterone and dihydrotestosterone propionates caused significantly greater increases $(P<0.001)$ in both seminal vesicle and ventral prostate weights than all other treatments. Testosterone also had a significantly greater effect $(P<0.02)$ on seminal vesicle weight than dihydrotestosterone. The propionates of the other four androgens increased seminal vesicle weights above control levels but the effect was only 


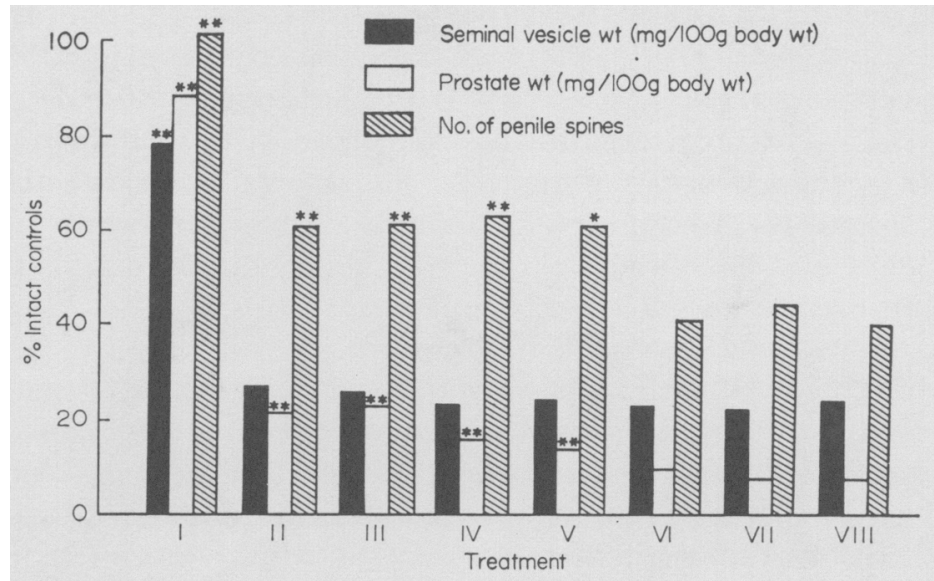

Text-Fig. 1. Relative organ weights and number of penile spines in castrated and castrated androgen-treated rats expressed as a percentage of the value for intact control rats. I, Dihydrotestosterone propionate; II, androstenedione propionate; III, androstanedione propionate; IV, $3 \alpha$-androstanediol propionate; $V$, androsterone propionate; VI, $3 \beta$-androstanediol propionate; VII, androstenediol propionate; VIII, oil vehicle. Columns marked with asterisks indicate values that are significantly different from those of oil-treated castrated controls: ${ }^{*} P<0.01,{ }^{* *} P<0.001$.

significant for androsterone $(P<0 \cdot 02)$. These four androgens also elevated prostate weights above control levels and differences were significant in each case. The result for androstanedione is biased by an abnormally high response in one animal; without this result, the mean would be $21.21 \mathrm{mg} / 100 \mathrm{~g}$ body weight. There is an indication from these results that the two diketone compounds, androstenedione and androstanedione, exerted a greater effect on the prostate than either $3 \alpha$-androstanediol or androsterone. This tendency was also observed in the previous experiments (Text-fig. 1).

Table 2. The effect of different androgens on seminal vesicle and ventral prostate weights of the castrated rats in Experiment 5

\begin{tabular}{|c|c|c|}
\hline Treatment $\uparrow$ & $\begin{array}{l}\text { Seminal vesicle weight } \\
(\text { mg } / 100 \mathrm{~g} \text { body wt }) \\
\quad(\text { mean } \pm S . E .)\end{array}$ & $\begin{array}{l}\text { Ventral prostate weight } \\
(\text { mg/100 g body wt }) \\
\quad(\text { mean } \pm S . E .)\end{array}$ \\
\hline $\begin{array}{l}\text { Testosterone } \\
\text { Dihydrotestosterone } \\
\text { Androstenedione } \\
\text { Androstanedione } \\
3 \alpha \text {-Androstanediol } \\
\text { Androsterone } \\
\text { Castrated + oil }\end{array}$ & $\begin{array}{l}94 \cdot 65 \pm 3 \cdot 92^{* * * *} \\
78 \cdot 40 \pm 3 \cdot 90^{* * * *} \\
31 \cdot 98 \pm 2 \cdot 32 \\
36 \cdot 96 \pm 4.03 \\
32 \cdot 51 \pm 2 \cdot 23 \\
35 \cdot 03 \pm 1 \cdot 84 \ddagger \\
27 \cdot 11 \pm 1 \cdot 52\end{array}$ & $\begin{array}{l}66 \cdot 39 \pm 3 \cdot 39 * * * * \\
68 \cdot 32 \pm 3 \cdot 67 * * * * \\
23 \cdot 29 \pm 2 \cdot 69 \ddagger \\
26 \cdot 37 \pm 5 \cdot 62^{*} \\
18 \cdot 86 \pm 2 \cdot 01 \ddagger \\
14 \cdot 23 \pm 0 \cdot 97 \ddagger \\
11 \cdot 29 \pm 0 \cdot 31\end{array}$ \\
\hline
\end{tabular}

† Five animals per group. Androgens given as propionates, $300 \mu \mathrm{g} / \mathrm{day}$ for 10 days.

Comparison with castrated controls: $\ddagger P<0.02 ; * P<0.05$; ****P<0.001. 


\section{DISGUSSION}

There are very few reports on the comparative activities of androgens in the adult castrated rat. Assay procedures are concerned with the ability of androgens to promote accessory organ growth in prepubertal castrates. The present experiments, however, were part of an investigation of androgenic involvement in sexual behaviour and therefore it was the ability of the steroids to maintain normal adult morphology that was studied.

Testosterone and androstenedione are normally considered to be the major androgens produced by the mammalian testes; the other androgens used in this study have all been isolated from the accessory organs. In male mice, after administration of radioactively-labelled testosterone, the following steroids were detected in the accessory sex glands: androstenedione; dihydrotestosterone; androsterone; androstenediol; $3 \alpha$-androstanediol (Applegren, 1970). Also, in castrated male rats after treatment with labelled testosterone or dihydrotestosterone, androstanedione and $3 \alpha$ - and $3 \beta$-androstanediol were found in seminal vesicles and prostate (Buric, Becker, Petersen \& Voigt, 1972).

In the first four experiments of the present study, castrated oil-injected controls showed a typical response to androgen deprivation. Both the weights of the accessory organs and the number of penile spines were significantly reduced. The effect on the penile spines was less marked than for the other two measures but the results give no indication of the reduction in spine size that also occurred. The number of spines responded to various treatments in a similar fashion to the prostate with significant differences being detected on the same occasions. There was generally a good agreement between the results of the first four experiments and Exp. 5 with regard to accessory sex organ response.

Dihydrotestosterone exerted a large peripheral effect in Exps 1 and 5; in Exp. 5, the effect on the prostate was comparable to that of testosterone. Originally it was shown that the prostate converted testosterone to dihydrotestosterone (Bruchovsky \& Wilson, 1968); more recently, this $5 \alpha$-reduction has been shown to occur in other peripheral sites (Appelgren, 1970) and also centrally (Kniewald, Massa \& Martini, 1971). Since it has been proposed that dihydrotestosterone may be the active form of testosterone in the prostate (Gloyna \& Wilson, 1969), it might be expected that the two androgens would have similar effects. Similar effects on penile spine numbers were found, confirming the results of Feder (1971) who also found dihydrotestosterone to have less effect on the seminal vesicles than testosterone. No significant differences in seminal vesicle weights were detected in an investigation using high doses of the free steroids (Whalen \& Luttge, 1971).

Testosterone and androstenedione are generally regarded as being interconvertible. Possibly, therefore, the effects of androstenedione are due to partial conversion to testosterone by organs such as the liver. Alternatively, it may undergo $5 \alpha$-reduction to androstanedione, a compound which can also be formed from dihydrotestosterone. Clearly, androstenedione and androstanedione are considerably less potent than testosterone. The seminal vesicles did not respond to either steroid after treatment for 5 weeks at $150 \mu \mathrm{g} /$ day (Exp. 3) 
or 10 days at $300 \mu \mathrm{g} /$ day (Exp. 5). Whalen \& Luttge (1971) also found the response of the seminal vesicles to free androstenedione was significantly less than to testosterone or dihydrotestosterone.

Androsterone, orginally isolated as the principal testosterone metabolite in the urine, was subsequently shown to be produced in vivo from either androstanedione or $3 \alpha$-androstanediol (Dorfman \& Hamilton, 1940). This latter compound is well known as a $5 \alpha$-reduction product of testosterone. For example, after administration of labelled testosterone, it has been found in vitro in the testis (Steinberger \& Ficher, 1971), in vivo and in vitro in the prostate (Bruchovsky \& Wilson, 1968) and in vivo in accessory organs and testis (Appelgren, 1970). The present results showed that neither androsterone nor $3 \alpha$-androstanediol were as potent as androstenedione. No effect on seminal vesicle weights was detected after treatment for 5 weeks although androsterone was found to have a significant effect in Exp. 5. The prostate response was more consistent; both compounds had a significant effect but, in each experiment, $3 \alpha$-androstanediol was the more androgenic.

It has been suggested that $3 \alpha$-androstanediol can be regarded as a weak form of dihydrotestosterone in that it promotes growth of the prostatic epithelium and, like dihydrotestosterone, does not support much secretory activity, as determined by the size of the Golgi bodies (Baulieu, 1970). From culture experiments, it has been shown that $3 \beta$-androstanediol has the opposite effect (Baulieu, Lasnitzki \& Robel, 1968). If this is the case, this latter metabolite of dihydrotestosterone would not be expected to have much effect on accessory sex organ weights. This was borne out by the results of the first series of experiments.

Androstenediol was included in this investigation as it is an example of a $\Delta^{5}$ compound. Unlike the other compounds, it has been implicated as being a precursor rather than a metabolite of testosterone. From studies in vitro with minced testis, it has been suggested that there are two main pathways of androgen formation, a $\Delta^{4}$ pathway by way of androstenedione and a $\Delta^{5}$ pathway by way of dehydroepiandrosterone, and possibly androstenediol, to testosterone (Slaunwhite \& Burgett, 1965; Yanaihara \& Troen, 1972a, b). Presumably, in the absence of the testes, conversion of androstenediol to testosterone will be minimal and consequently it is unlikely to have much peripheral action. This is supported by the results of Exp. 4 .

In an 8-week study, it was found that the minimum daily dose of testosterone propionate required to maintain normal accessory sex organ weights in castrated adult rats was $100 \mu \mathrm{g} /$ day (Davidson \& Bloch, 1969). In the first series of experiments described here, $150 \mu \mathrm{g}$ dihydrotestosterone propionate/day ( 5 days per week for 5 weeks) was nearly sufficient to maintain normal organ weights. Since Exp. 5 showed testosterone and dihydrotestosterone to be equivalent in potency, it can be assumed that the same dose of testosterone would produce similar effects. If this dose is representative of physiological levels in the intact animals, the other androgens tested, which are likely to be present in smaller amounts anyway, must contribute very little to the overall peripheral effect. On an activity basis, the various androgens fall into three groups, and since they differ in molecular structure at three carbon sites (C3, 
C4/5 and C17), activity can be related to structure (Table 3 ). Firstly, it appears that $5 \alpha$-reduction of $\mathrm{C} 4$ has little effect on androgenicity. Secondly, whilst $\alpha$-reduction of the ketone at C3 has a negligible effect, $\beta$-reduction seriously affects androgenicity. This is not to say that $3 \beta$-compounds are inactive as they may be involved in maintenance of secretory processes. Thirdly, the greatest activity is conferred by an hydroxyl group at C17, the ketone being less active. These conclusions are basically in agreement with previous structure/ activity studies in the immature rat (Segaloff \& Gabbard, 1962; Liao \& Fang, 1969).The results presented for the numbers of penile spines suggest that the above conclusions are applicable to these structures also. By subtraction of the spine count for the oil-treated controls from those for the various androgen treatments, it appears that the penile spines are more sensitive to exogenous androgen treatment than the seminal vesicles and in some cases, more sensitive than the ventral prostate. These results refer specifically to numbers of spines

Table 3. Molecular structure of androgens and their relative activities determined by relative prostate weights of castrated rats expressed as a percentage of intact controls in Exps 1 to 4

\begin{tabular}{l|c|c|c|c}
\hline \multicolumn{1}{c|}{ Androgen } & $\begin{array}{c}\% \text { Relative } \\
\text { activity }\end{array}$ & \multicolumn{3}{|c}{ Molecular structure } \\
\cline { 2 - 4 } & - & $C 3$ & $C 4 / 5$ & $C 17$ \\
\hline Testosterone & $=\mathrm{O}$ & $\Delta^{4}$ & $\beta \mathrm{OH}$ \\
Dihydrotestosterone & 88 & $=\mathrm{O}$ & $5 \alpha \mathrm{H}$ & $\beta \mathrm{OH}$ \\
\hline Androstenedione & 21 & $=\mathrm{O}$ & $\Delta^{4}$ & $=\mathrm{O}$ \\
Androstanedione & 22 & $=\mathrm{O}$ & $5 \alpha \mathrm{H}$ & $=\mathrm{O}$ \\
3a-Androstanediol & 15 & $\alpha \mathrm{OH}$ & $5 \alpha \mathrm{H}$ & $\beta \mathrm{OH}$ \\
Androsterone & 13 & $\alpha \mathrm{OH}$ & $5 \alpha \mathrm{H}$ & $=\mathrm{O}$ \\
\hline 3 $\beta$-Androstanediol & 9 & $\beta \mathrm{OH}$ & $5 \alpha \mathrm{H}$ & $\beta \mathrm{OH}$ \\
Androstenediol & 7 & $\beta \mathrm{OH}$ & $\Delta^{5}$ & $\beta \mathrm{OH}$ \\
\hline
\end{tabular}

although spine size also appears to be androgen-dependent. The comparatively gradual decline in the number of spines in the control group may reflect the slow rate of androgen metabolism in skin tissue (Hsia, 1971).

\section{ACKNOWLEDGMENTS}

This project was supported by Grant No. G 970/302B from the Medical Research Council. The author is grateful to Mr G. Stodulski for propionation of the androgens.

\section{REFERENCES}

Adler, N. \& Bermant, G. (1966) Sexual behaviour of male rats: effects of reduced sensory feedback. 7. comp. physiol. Psychol, 61, 240.

AppelgRen, L. (1970) Chromatographic studies and scintillation counting of selected tissues of mice implanted with labelled testosterone. Biol. Reprod. 3, 128. 
Baulieu, E. E. (1970) The action of hormone metabolites: a new concept in endocrinology (on the metabolism and the activity of testosterone). Revue Etud. clin. biol. 15, 723.

Baulieu, E. E., Lasnitzki, I. \& Robel, P. (1968) Metabolism of testosterone and action of metabolites on prostate glands grown in organ culture. Nature, Lond. 219, 1155.

BEACH, F. A. \& Levinson, G. (1950) Effects of androgen on the glans penis and mating behaviour of castrated male rats. J. exp. Zool. 114, 159.

BEAGH, F. A. \& NuCCI, L. P. (1970) Long-term effects of testosterone phenylacetate on sexual morphology and behaviour in castrated male rats. Horm. E' Behav. 1, 223.

Bruchovsky, N. \& WiLson, J. D. (1968) The conversion of testosterone to $5 \alpha$-androstan-17 $\beta$-ol-3-one by rat prostate in vivo and in vitro. 7. biol. Chem. 248, 2012.

Buric, L., Becker, H., Petersen, C. \& Voigt, K. D. (1972) Metabolism and mode of action of androgens in target tissues of male rats. 1. Metabolism of testosterone and $5 \alpha$-dihydrotestosterone in target organs and peripheral tissues. Acta endocr., Copenh. 69, 153.

Davinson, J. M. (1966) Characteristics of sex behaviour in male rats following castration. Anim. Behav. 14, 266.

Davidson, J. M. \& Bloch, G. J. (1969) Neuroendocrine aspects of male reproduction. Biol. Reprod. 1,67 .

Dorfman, R. I. (1962) Androgens and anabolic agents. In Methods in Hormone Research, Vol. 2, p. 275. Ed. R. I. Dorfman. Academic Press, New York and London.

Dorfman, R. I. \& Hamilton, J. B. (1940) Concerning the metabolism of testosterone to androsterone. 7. biol. Chem. 133, 753.

FEDER, H. H. (1971) The comparative actions of testosterone propionate and $5 \alpha$-androstan-17 $\beta$-ol-3-one propionate on the reproductive behaviour, physiology and morphology of male rats. 7. Endocr. $51,241$.

Gloyna, R.E. \& Wilson, J. D. (1969) A comparative study of the conversion of testosterone to $17 \beta$ hydroxy-5 $\alpha$-androstan-3-one (dihydrotestosterone) by prostate and epididymis. 7 . clin. Endocr. Metab. 29, 970.

Hsia, S. L. (1971) Potentials in exploring the biochemistry of human skin. In Essays in Biochemistry, Vol. 7, pp. 1-38. Ed. P. N. Campbell and F. Dickens. Academic Press, London.

KNIEWAid, Z., MASSA, R. \& MARTini, L. (1971) Conversion of testosterone into $5 \alpha$-androstan-17 $\beta$-ol3-one at the anterior pituitary and hypothalamic level. In Hormonal Steroids, p. 784. Excerpta Medica Cong. Series, No. 219, Amsterdam.

Liao, S. \& FANG, S. (1969) Receptor proteins for androgens and the mode of action of androgens on gene transcription in the ventral prostate. Vitams Horm. 27, 18.

Lyons, W. R., Berlin, I. \& Friedlander, S. (1942) Cornification of balano-preputial epithelium in normal rats and castrated rats treated with testosterone propionate. Endocrinology, 31, 659.

McDonald, P., Beyer, C., Newton, F., Brien, B., Baker, R., Tan, H. S., Sampson, C., Kitching, P., Greenhill, R. \& Pritchard, D. (1970) Failure of $5 \alpha$-dihydrotestosterone to initiate sexual behaviour in the castrated male rat. Nature, Lond. 227, 964

Parrott, R. F. (1972) Peripheral effects of some propionated androgens in the castrate male rat. 7. Reprod. Fert. 31, 518.

Segaloff, A. \& GabBard, R. B. (1962) Steroid structure and androgenicity. Endocrinology, 71, 949.

Slaunwhite, W. R. \& Burgett, M. J. (1965) In vitro testosterone synthesis by rat testicular tissue. Steroids, 6, 721.

Steinberger, E. \& Ficher, M. (1971) Formation and metabolism of testosterone in testicular tissues of immature rats. Endocrinology, $89,679$.

Whalen, R. E. \& Luttge W. G. (1971) Testosterone, androstenedione and dihydrotestosterone: effects on mating behaviour of male rats. Horm. \& Behav. 2, 117.

Yanainara, T. \& Troen, P. (1972a) Studies of the human testis. 1. Biosynthetic pathways for androgen formation in human testicular tissue in vitro. $\mathcal{7}$. clin. Endocr. Metab. 34, 783.

Yanaihara, T. \& Troen, P. (1972b) Studies of the human testis. 2. Study of androstenediol and its monosulphate in human testes in vitro. F. clin. Endocr. Metab. 34, 793. 